\title{
O texto natural: sobre a tarefa nietzschiana de "retraduzir o homem de volta à natureza"
}

\author{
The natural text: about the Nietrschean task \\ to "re-translate man back to nature"
}

\begin{abstract}
Alice Medrado ${ }^{1}$
Universidade Federal de Minas Gerais (UFMG), Belo Horizonte, MG, Brasil, e-mail: alicemedrado@yahoo.com.br
\end{abstract}

\section{Resumo}

Este texto traz uma interpretação do aforismo 230 de Além de Bem e Mal, em que Nietzsche define sua tarefa como aquela de "retraduzir o homem de volta à natureza". Tomamos a metáfora filológica como fio condutor em nossa investigação acerca das afirmações nietzschianas no sentido de recuperar o "eterno texto básico homo natura", buscando traços da filologia cética desenvolvida por Nietzsche em sua juventude que permitam uma certa abordagem de sua tentativa madura de superação do discurso moderno sobre a natureza humana. Por fim, situamos brevemente os pontos programáticos de BM 230 em relação ao contexto

1 Este texto é uma adaptação de uma seção de sua dissertação de mestrado, Tentativas e tentações naturalistas na filosofia de Nietžsche, defendida em 2014. 
geral da obra Além de Bem e Mal; em particular, tomamos o tratamento do tema da vontade de verdade e honestidade intelectual presentes em BM 230 como uma pista importante para compreensão do programa de "filosofia do futuro" anunciado em Além de Bem e Mal.

Palavras-chave: Natureza humana. Vontade de verdade. Filologia cética. Além de Bem e Mal.

\section{Abstract}

This text carries out an interpretaton of paragraph 230 of Beyond Good and Evil, in which Nietzsche defines his task as that of "translating man back to nature". We take the philologic metaphor as a guideline to our investigation on nietzschean claims to retrieve the "eternal basic text homo natura", seeking for traits of the skeptic philology developed by Nietzsche in his youth, ones that allow a certain approach to his mature attempt to overcome modern discourse on human nature. At last, we briefly locate the program points featuring BGE 230 in the general context of the oeuvre Beyond Good and Evil; particularly, we take the treatment dispensed to the theme of will to truth and intellectual honesty in BGE 230 as an important hint to understanding the program of "philosophy of the future" announced in Beyond Good and Evil.

Keywords: Human nature. Will to truth. Skeptic philology. Beyond Good and Evil.

Por fim se considere que mesmo o homem do conhecimento, ao obrigar seu espírito a conhecer, contra o pendor do espírito e também, com freqüência, os desejos de seu coração - isto é, a dizer Não, onde ele gostaria de aprovar, amar, adorar - atua como um artista e transfigurador da crueldade; tomar as coisas de modo radical e profundo já é uma violação, um querer-magoar a vontade fundamental do espírito, que incessantemente busca a aparência e a superfície - em todo querer-conhecer já existe uma gota de crueldade. (BM 229). 
(...) São palavras belas, solenes, reluzentes, tilintantes: honestidade, amor à verdade, amor à sabedoria, sacrifício pelo conhecimento, heroísmo do que é veraz - há algo nelas que faz subir o orgulho. Mas nós, eremitas e marmotas, há muito nos persuadimos, no fundo segredo de uma consciência eremita, que também essa digna pompa verbal é parte do velho enfeite-mentira, poeira e purpurina da inconsciente vaidade humana, e que também sob uma cor e uma pintura tão lisonjeiras deve ser reconhecido, uma vez mais, o terrível texto básico bomo natura. Retraduzir o homem de volta à natureza; triunfar sobre as muitas interpretações e conotações vaidosas e exaltadas que até o momento foram rabiscadas e pintadas sobre o eterno texto homo natura; fazer com que no futuro o homem se coloque frente ao homem tal como hoje, endurecido na disciplina da ciência, já se coloca frente à outra natureza, com intrépidos olhos de Édipo e ouvidos tapados como os de Ulisses, surdo às melodias dos velhos, metafísicos apanhadores de pássaros, que por muito tempo lhe sussurraram: "Você é mais! É superior! Tem outra origem!" - essa pode ser uma louca e estranha tarefa, mas é uma tarefa - quem o negaria: Por que a escolhemos, essa tarefa? Ou, perguntando de outro modo: "Por que conhecimento, afinal?". Todos nos perguntarão isso. E nós, premidos desse modo, nós, que já nos fizemos mil vezes a mesma pergunta, jamais encontraremos resposta melhor que... (BM 230)

Nesta que é uma das peças mais citadas e de mais difícil compreensão da obra nietzschiana encontramos a única ocorrência da promessa de "retraduzir o homem de volta à natureza". Em nenhum outro lugar da obra publicada Nietzsche define sua tarefa exatamente nesses termos: embora até o fim Nietzsche se refira orgulhosamente a suas habilidades em filologia enquanto metáfora para a arte de rigorosa interpretação do mundo e de si mesmo, é somente em BM 230 que se encontra a menção ao "terrível texto básico homo natura" ou "eterno texto homo natura". A ocorrência dessas expressões faz com que, dentre todos os aforismos programáticos da obra nietzschiana publicada, BM 230 soe particularmente ambicioso e enigmático ${ }^{2}$.

2 Posteriormente, em O Caso Wagner, Nietzsche diz ter encontrado na Carmen de Bizet "o amor retraduzido em natureza!”: "Endlich die Liebe, die in die Naturzurückübersetzte Liebe!” CW 2. Seria preciso uma análise mais detida da obra nietzschiana como um todo para avaliar em que medida poderia haver aqui um indício de mudança de projeto, já que o filósofo, nessa ocasião, não mais fala de retraduzir (ou reconduzirir, transportar de volta, o verbo zurückü̈bersetzten, usado em ambas ocorrências, guarda algo desse sentido) o "homem" mas "o amor" em natureza; além disso, diferentemente de BM, o contexto dessa afirmação em O Caso Wagner se limita, à primeira 
A definição dessa "tarefa" é precedida por considerações sobre a honestidade e sua relação com a crueldade, apresentadas no aforismo anterior, BM 229, que se refere à vontade de conhecimento como uma "violação" da "vontade fundamental do espírito". BM 230 começa com um esclarecimento do que seria essa "vontade fundamental do espírito", ou antes, aponta pra uma dualidade fundamental. "Esse imperioso algo a que o povo chama espírito" é apresentado primeiramente como algo que "tem a vontade de conduzir da multiplicidade à simplicidade, uma vontade restritiva, conjuntiva, sequiosa de domínio e realmente dominadora." (BM 230). Ao que tudo indica, esse traço fundamental do espírito seria expressão do "princípio de identidade", que segundo Afrikan Spir é a estrutura mais básica e indispensável de nosso aparato cognitivo, isto é, o princípio que faz com que vejamos o mundo como entidades simples e discretas, reconduzindo o múltiplo ao uno - esta tendência Nietzsche associa a um impulso de "dominação".

Ao longo do aforismo Nietzsche aponta, ao que parece, 7 desdobramentos dessa tendência primordial, referentes a necessidades e faculdades que seriam "as mesmas que os fisiólogos apresentam para tudo que vive, cresce e se multiplica", quais sejam: "assimilar o novo ao antigo"; "simplificar o complexo"; "rejeitar ou ignorar o inteiramente contraditório"; "enquadrar novas coisas em velhas divisões"; "não saber" até aqui, predomina o signo da "assimilação", cujo campo semântico remete ao sistema digestivo e metabólico, sentido que é reforçado pela sequência do aforismo, em que se encontra a ideia de que o grau de assimilação dependeria da "força digestiva" do espírito, uma vez que o "espírito" se assemelha mais que tudo a um estômago". Essa imagem leva a pensar que

vista, àquele de um comentário estético. Uma hipótese é de que Nietzsche teria redirecionado seu projeto de naturalização a uma aplicação localizada na "fisiologia da arte". Cf. RAMATTIOTI, 2012; CHAVES, 2007. Essa discussão, no entanto, extrapola o escopo deste artigo.

3 Filósofo ucraniano, neo-kantiano. Autor de Denken und Wirklichkeit (Pensamento e Efetividade, 1873). Nietzsche travou contato com o pensamento de Spir logo cedo em seu trajeto intelectual, quando estava compondo suas primeiras obras filosóficas; ele releu Denken und W irklichkeit várias vezes, inclusive quando da redação de Além de Bem e Mal. William Mattioli explica que: "Nietzsche se apropriou e reinterpretou várias teses e temas presentes na reformulação da teoria kantiana do transcendental proposta por Spir. Alguns dos aspectos centrais desse projeto de reelaboração teórica são, por um lado, a recondução do a priori a um único elemento constitutivo, o princípio de identidade, o qual nos forneceria o conceito de Ser e de incondicionado e, por outro, a afirmação de uma extensão ontológica desse conceito.” (MATTIOLI, 2013, p. 328). Ver também D’IORIO, 1993. 
o espírito se "alimenta" de mundo, rejeita ou absorve conteúdos segundo suas capacidades e necessidades - rejeita certos dados instintivamente vistos como desnecessários ou potencialmente nocivos, "venenosos" talvez, os quais prefere ignorar, não saber, e outros conteúdos o espírito absorve e reconduz às funções mais profundamente incorporadas, predominando a preferência prudencial pelo que já é conhecido. Pode-se pensar que "enquadrar novas coisas em velhas divisões” seja uma estratégia de redução do gasto energético envolvido nesse processo, sendo portanto uma atividade definida por um princípio de economia; essa função também remete a um segundo sentido de "assimilar" enquanto "tornar similar", que se liga ao impulso à simplificação, em que o traço dominador aparece mais claramente 4 .

A metáfora do espírito como estômago aparece na sequência da apresentação dessas cinco primeiras funções cognitivas, e então se segue a referência a mais duas funções: "deixar-se iludir" e "iludir outros espíritos e disfarçar-se diante deles”. A primeira se ligaria a um desejo de fruição da própria "arbitrariedade", de forma que o espírito chega a suspeitar que "as coisas não são assim, de que apenas se convenciona que sejam assim” mas se satisfaz por "um gosto na incerteza e ambiguidade". A segunda função expressa a atividade espiritual de criar máscaras, metamorfosear-se, camuflarse, e seria um mecanismo de proteção e esconderijo, além de oportunidade de fruição com a própria criatividade. Por razões de simplificação, podemos nos referir a essa primeira tendência do espírito, explorada por Nietzsche em termos tão ricos, como referentes à tendência à "falsificação". O próprio Nietzsche as resume como expressão de "vontade de aparência, de simplificação, de máscara, de manto, enfim, de superfície - pois toda superfície é um manto".

Laurence Lampert (2001) captou muito bem as implicações dessa visada nietzschiana sobre a inclinação natural do espírito:

A clarificação de Nietzsche da vontade básica do espírito destaca a naturalidade do costume, das crenças e das práticas que representam equivocadamente o mundo para dominá-lo. $\mathrm{O}$ antinatural é natural para o espírito da humanidade; ele naturalmente opõe as verdades palpáveis mas indigestas da natureza tal como a natureza animal da humanidade, que Nietzsche está inclinado a deixar escapar (229).

4 Vale lembrar que o vocabulário da assimilação é utilizado na sociologia para se referir aos processos de acolhimento e incorporação de grupos minoritários pelas culturas hegemônicas. 
A vontade básica do espírito humano o inclina poderosamente para o cosmético, para superfícies mentirosas, e a filosofia até aqui permitiu e incentivou essa inclinação natural. (LAMPERT, 2001, p. 228) 5 .

Ao que nos parece, Nietzsche de fato aponta para um certo acordo entre senso comum e boa parte da tradição filosófica no sentido de incentivar essa tendência primordial do espírito, tendência que no entanto encontraria uma contraposição no "homem do conhecimento", cujo "pendor" estaria em "tomar e querer tomar as coisas de modo profundo, plural, radical". Enquanto a primeira tendência fundamental do espírito, em seus vários desdobramentos, poderia ser resumida como uma "vontade de falsificação", esta segunda tendência fundamental se identifica com "uma espécie de crueldade da consciência e do gosto intelectuais". Essa seria uma disposição cruel do espírito, em primeiro lugar, por estabelecer-se fundamentalmente como resistência à sua própria tendência mais básica, que é a tendência à falsificação; isto é sugerido no aforismo anterior, BM 229, onde se reivindica a expansão do conceito de crueldade para abarcar não só o gozo com o sofrimento alheio, mas também o gozo com o próprio sofrimento.

$\mathrm{O}$ impulso ao conhecimento se liga à crueldade na medida em que expõe o sujeito cognoscente a tudo aquilo que os mecanismos prudenciais mais incorporados o fazem evitar: o múltiplo, o novo, o desconhecido, a nuance, a diferença. O "homem do conhecimento" faz violência a si mesmo ao afastar-se dessa prudência e expor-se aos efeitos potencialmente corrosivos da verdade. Para Nietzsche, esse impulso ao conhecimento por vezes é visto como uma "extravagante honestidade", termo que o próprio filósofo diz considerar ainda demasiado suave, apenas uma sutileza própria de homens "virtuosos e amáveis". Nos termos do próprio Nietzsche, que nesse aforismo se dirige ao leitor da forma mais direta possível, trata-se de crueldade, dureza e disciplina - disposições de espírito cultivadas pela "disciplina da ciência" e convocadas à tarefa de recuperação do "terrível texto básico homo natura".

Nesse ponto começam os problemas de interpretação do aforismo. Como é possível que o homem, enquanto animal não fixado, chegue a dispor de um "eterno texto" natural? Se milênios de seleção social, sob vigência da cultura moral, atuaram sobre hábitos, instintos, práticas cognitivas, práticas

5 Todas as citações de obras em língua inglesa que ocorrem no corpo do texto foram livremente traduzidas. 
sexuais e valores humanos, em que sentido se pode pensar num homo natura? Se a atuação da seleção social ${ }^{6}$ fez do homem um palimpsesto, como recuperar o texto básico? O que haveria de atual e efetivo nesse texto original? Trata-se de um texto original e extraviado ou de um texto "fundamental", no sentido de que ainda serve de alicerce para as camadas mais recentes e superficiais? O palimpsesto esconde uma natureza mais natural? O erro, a simplificação, a exaltação vaidosa com que se escreveu o palimpsesto não seriam afinal expressão dessa mesma natureza? A tarefa que se coloca é uma tarefa arqueológica em que se deve cavar por baixo das camadas mais recentes da "pintura"? Ou é mesmo uma tarefa de tradução, no sentido de trazer para uma linguagem mais primitiva a configuração atual do homem, ou trazer para uma linguagem mais atual as camadas mais primitivas que ainda atuam no homem? É possível, é desejável retornar a uma primeira natureza? É esse o sentido da tarefa?

Como não parece haver qualquer resposta direta e inequívoca a essas questões, vamos proceder por remoção, endereçando primeiro as interpretações sobre as quais o filósofo deseja "triunfar": estas seriam "as muitas interpretações e conotações vaidosas e exaltadas que até o momento foram rabiscadas e pintadas sobre o eterno texto bomo natura" ou "melodias dos velhos, metafísicos apanhadores de pássaros, que por muito tempo lhe sussurraram: 'Você é mais! É superior! Tem outra origem!”'. A primeira referência que temos, portanto, são às interpretações morais de cunho metafísico que atribuíram ao homem uma origem ou uma destinação divinas. Valendo-nos das poucas pistas que temos aqui, passemos a uma breve consideração sobre a vaidade, como forma de melhor compreendermos a crítica às interpretações metafísicas.

6 O termo "seleção social" não é usado por Nietzsche, mas desenvolvido como recurso interpretativo por John Richardson. Na tentativa de esclarecer alguns paradoxos da filosofia nietzschiana por meio de uma harmonização desta com a biologia evolucionista, Richardson reconstitui uma narrativa que apresenta o homem como produto tanto de um processo de seleção natural quanto de seleção sociocultural. Enquanto a seleção natural atuaria sobre os impulsos do organismo, a seleção social operaria uma triagem de hábitos e valores a serem incentivados. Esses dois âmbitos da evolução se dariam de forma simultânea e por sobreposição, ou seja, impulsos atuam sobre valores e hábitos, valores e hábitos atuam sobre impulsos - ora incentivando-os, ora fazendo-os retroceder. A seleção social seguiria fundamentalmente uma lógica de grupo, que favorece aqueles hábitos mais facilmente assimiláveis e replicáveis por seus membros; seu principal produto seria a sedimentação daquilo que Nietzsche chama "instinto de rebanho". Cf. RICHARDSON, 2004. 
A vaidade, Nietzsche sugere em outro aforismo, consiste num mecanismo em que os seres "buscam criar de si uma opinião boa que eles mesmos não têm - e portanto não 'merecem' também -, e que no entanto passam a crer posteriormente nessa boa opinião" (BM 261). Ao longo desse aforismo, desenvolve-se a ideia de que a força que atua no vaidoso é na verdade um traço de submissão às valorações que lhe são atribuídas por outrem, uma transferência da capacidade de autoavaliação para uma outra pessoa ou instituição. No caso das "interpretações vaidosas" rabiscadas sobre o "texto homo natura", haveria, portanto, um caso de submissão aos valores criados por "velhos metafísicos, apanhadores de pássaros", interpretações que, na verdade, contribuíram tanto para exaltar quanto para colocar sobre o homem o peso de todo um vocabulário do pecado, da culpa, da danação.

O vaidoso coloca-se numa situação de extrema suscetibilidade, ficando vulnerável a qualquer tipo de opinião e valoração, nem sempre positivas:

O vaidoso se alegra de cada opinião boa que ouve sobre si (independente de qualquer ponto de vista de utilidade, e também não considerando se é falsa ou verdadeira), assim como sofre de cada opinião ruim: pois ele se submete a ambas, ele se sente submetido a elas, por esse antigo instinto de submissão que nele irrompe. (BM 261).

Uma vez que o impulso à submissão leva o vaidoso a desconsiderar os fatores de veracidade e utilidade das opiniões, ele se torna mais suscetível também a uma relação "exaltada" com essas opiniões. Para Nietzsche, o traço fundamental da vaidade, o "instinto de submissão", denuncia sua origem "escrava", por oposição ao ponto de vista do nobre, cujo ímpeto maior está em "só por si arrogar um valor e 'pensar bem' de si" (BM 261). O filósofo aponta que com a ascensão da democracia, vista como uma ocasião de mistura entre moral escrava e nobre, há uma tendência à derrocada do comportamento vaidoso, de forma que se poderia afirmar que "a vaidade é um atavismo." (BM 261). A derrocada do comportamento vaidoso na modernidade é vista como um fato positivo, claro, uma vez que falta às opiniões vaidosas qualquer aporte de veracidade ou utilidade. Não há dúvidas de que Nietzsche vê esse momento como uma oportunidade para a construção de uma visão mais justa do humano ${ }^{7}$.

7 A superação da submissão envolvida no comportamento vaidoso, por outro lado, ecoa o tema kantiano da maioridade, que na verdade reaparece com uma certa constância ao longo de BM, 
Às interpretações vaidosas e exaltadas, Nietzsche contrapõe sua própria interpretação, apresentada de forma mais direta que o usual, num aforismo cujo tom é carregado de crueldade:

O homem, um animal complexo, mendaz, artificial, intransparente, e para os outros animais, inquietante, menos pela força que pela astúcia e inteligência, inventou a boa consciência para chegar a fruir sua alma como algo simples; e toda a moral é uma decidida e prolongada falsificação, em virtude da qual se torna possível a fruição do espetáculo da alma. Desse ponto de vista, o conceito de "arte" incluiria bem mais do que normalmente se crê. (BM 291).

A crueldade aqui está em trazer à tona sem qualquer recurso atenuante aquilo que mais contraria as interpretações vaidosas do homem: o fato de que o homem é um animal. É neste sentido, nos parece, que devemos tomar a indicação importante, trazida em BM 230 segundo a qual o homem deve colocar-se "frente ao homem tal como hoje, endurecido na disciplina da ciência, já se coloca frente à outra natureza", ou seja, no sentido de reconhecer no homem as mesmas atividades que se observam no mundo natural - algo que Nietzsche avança, por exemplo, ao atribuir ao espírito funções "metabólicas": assimilação, rejeição, funções "alimentares" - mas, acima de tudo, esta é uma indicação de que a investigação sobre o humano deve se dar em acordo com uma disposição de espírito "endurecida na disciplina da ciência", ou seja, que esta investigação deve se pautar por princípios de sobriedade, economia, simplicidade, desmistificação, e abertura aos resultados científicos disponíveis.

A caracterização de sua natureza animal como fundada em mendacidade, artificialidade, intransparência, traz a sugestão paradoxal de que há um fator natural que faz o homem querer se distinguir da natureza. Por outro lado, a única distinção que Nietzsche parece admitir como procedente, ou antes, a qualificação nietzschiana da especificada do homem em relação aos outros animais seria sua "não fixação". O homem como "animal não

ver, por exemplo BM 34 e 35. Apesar de declarar guerra à ilustração democrática já no prólogo de BM, Nietzsche parece acalentar sua própria versão de uma aposta iluminista; a este respeito, ver o comentário de Lampert: "The New Enlightenment is a prospective title often used in the notebooks containing materials that eventually appeared under the title Beyond Good and Evil (for example, KSA 11.26 [293, 298]; 27 [79]; 29 [40]). Nietzsche's task is itself an enlightenment that carries forward the Greek enlightenment prior to the Platonic strategy that reconciled that enlightenment with popular prejudice.” (LAMPERT, 2001, p. 16). 
fixado" é mencionado já em BM 62; essa expressão parece traduzir a ideia de que o homem seria um animal de história evolutiva recente, cujos recursos adaptativos ainda não teriam chegado a um equilíbrio estável como o dos demais animais, o que the abriria uma miríade de modos de vida possíveis. Ter isto em mente ajuda a entender a afirmação seguinte, um tanto irônica, de que o conceito de "arte" pode ser expandido para incluir "bem mais do que normalmente se crê": o contexto do aforismo leva a pensar que o que aí deve ser incluído é toda falsificação e autoengano que tornam o mundo humanamente habitável (satisfazendo a primeira vontade fundamental do espírito), bem como a "boa consciência" com essa condição artificial. A afirmação é de que não só a arte, mas toda moral estaria a serviço desse impulso primordial à falsificação, a começar pela falsificação da realidade mais próxima, a realidade da própria alma humana. O conceito de "arte" nesse sentido pode incluir os artifícios da moral. No cenário que se delineia aqui vê-se que o homem, enquanto animal não fixado, precisa ajustar para si um mundo falsificado, fixar para si um ambiente antinatural, o que, por intrigante que seja, é para ele uma necessidade vital. Na verdade, Nietzsche parece apontar a necessidade de falsificar o mundo como compartilhada em algum grau por todo vivente, na medida mesma em que cada ser vivo configura uma perspectiva e necessita organizar-se. Mas enquanto animal não fixado, o homem teria desenvolvido mecanismos mais complexos de falsificação, e além de mais complexos, mecanismos não estabilizados, de forma que necessitaria viver constantemente sob tentativas de ajuste, dentre as quais se inclui a coerção moral a essa natureza primeira, amorfa ou talvez polimorfa, e potencialmente destrutiva.

A moral seria fundamentalmente um mecanismo de autoengano, de má compreensão da vida espiritual humana, uma tal que paradoxalmente permite fruir do "espetáculo da alma". Por mais enviesada que seja, a visada moral é, afinal, um instrumento que permite ao homem cognição de si mesmo, e um tipo de cognição que guarda uma certa relação de afinidade com a "tendência fundamental do espírito" que discutimos acima. Mas isto não leva à ideia de que a moral, portanto, seria expressão de uma necessidade natural?

Essa questão fundamental já havia sido endereçada no primeiro capítulo do livro, em que Nietzsche aponta os paradoxos a que a filosofia estoica é levada em razão de tomar como princípio a possibilidade de viver "conforme a natureza", frente ao qual o filósofo indaga: "Viver - isto não é 
precisamente querer ser diverso dessa natureza: Viver não é avaliar, preferir, ser injusto, ser limitado, querer ser diferente?" (BM 9).

O ponto da relação entre natureza e moral é finalmente desenvolvido num outro aforismo:

Toda moral é, em contraposição ao laisser aller [“deixar ir"], um pouco de tirania contra a "natureza", e também contra a "razão": mas isso ainda não constitui objeção a ela, caso contrário se teria de proibir sempre, a partir de alguma moral, toda espécie de tirania e desrazão. O essencial e inestimável em toda moral é o fato de ela ser uma demorada coerção (...). Mas o fato curioso é que tudo o que há e houve de liberdade, finura, dança, arrojo e segurança magistral sobre a Terra, seja no próprio pensar, seja no governar, ou no falar e convencer, tanto nas artes como nos costumes, desenvolveu-se apenas graças à "tirania de tais leis arbitrárias"; e, com toda a seriedade, não é pequena a probabilidade de que justamente isso seja "natureza" e "natural" - e não aquele laisser aller! (BM 188).

Estamos diante da afirmação da "probabilidade" de que a natureza humana se caracterize justamente por um impulso de distinguir-se da natureza, e de que o instrumento mais eficaz para a satisfação desse impulso foi precisamente a moral. As formulações a que se chega são certamente intrigantes: a moral seria a um tempo um pouco de "tirania contra a natureza", o que não veta a probabilidade de que a tirania contra a natureza seja "natural".

Não se encontra aqui a proposta de naturalização dos conteúdos morais $^{8}$, claro, mas a suspeita de que justamente o aspecto arbitrário e infundado desses conteúdos dá um testemunho do que o homem é: um animal que tem a cultura como parte de sua etologia, e que portanto vive a sobreposição e mesmo a contradição dos processos de seleção biológica e de seleção social, haja visto que a seleção social apresenta uma lógica própria e menos sedimentada que a seleção natural. Num certo sentido, no entanto, a submissão a leis arbitrárias parece ser apontada como apenas uma etapa na história do homem, ao menos na história do homem europeu; esta seria uma etapa que viabilizou o surgimento da própria liberdade, até

8 Se o mero fato de que o aspecto tirânico de toda moral "não chega a constituir uma objeção", isto de forma alguma neutraliza as objeções de Nietzsche à "moral no sentido pejorativo", ancorada em pressupostos metafísicos, com pretensões universalizantes. O conteúdo dessa moral é sumamente objetável. 
mesmo a liberdade "no próprio pensar", e esta, por sua vez, pressiona o homem moderno a reinventar tais leis e avançar uma nova compreensão do material pulsional por tanto tempo coagido pela moral. Ou seja, o ponto de vista moral, e todas suas implicações práticas, seriam um dado irreversível da história ocidental, o que não quer dizer que não possa ser superado, ou mesmo "autossuperado", como afirma Nietzsche. E isto, mais uma vez, reforça o sentido de maleabilidade que Nietzsche atribui à natureza humana.

$\mathrm{Na}$ sequência do aforismo, Nietzsche elenca as principais exigências morais que marcaram essa história:

A prolongada sujeição do espírito, a desconfiada coerção na comunicação dos pensamentos, a disciplina que se impôs o pensador, a fim de pensar sob uma diretriz eclesiástica ou cortesã ou com pressupostos aristotélicos, a duradoura vontade espiritual de interpretar todo acontecimento segundo um esquema cristão e redescobrir e justificar o Deus cristão em todo e qualquer acaso tudo o que há de violento, arbitrário, duro, terrível e antirracional nisso revelou-se como o meio através do qual o espírito europeu viu disciplinada a sua força, sua inexorável curiosidade e sutil mobilidade: mesmo reconhecendo a quantidade insubstituível de força e espírito que aí teve de ser sufocada, suprimida e estragada (pois nisso, como em tudo, a natureza se mostra como é, em toda a sua magnificência pródiga e indiferente, que nos revolta, mas que é nobre). (BM 188)

O que há de curioso nesse aforismo é que Nietzsche parte de uma consideração sobre uma série de acidentes e vicissitudes que determinaram o curso da cultura intelectual europeia, reconhecendo que estes estão igualmente sob o signo do "violento, arbitrário, duro, terrível e antirracional", mas o filósofo parece encontrar nesses acidentes um indício do que a natureza é. A primeira conclusão que Nietzsche parece extrair é que não há uma adequação entre a natureza humana e a verdade, principalmente, que a natureza humana não é autotransparente, e que não se deve esperar encontrar qualquer tipo de correção epistêmica entre os pressupostos da moral e a natureza; segundo, que por meio de exigências as mais arbitrárias como a de "interpretar todo acontecimento segundo um esquema cristão e redescobrir e justificar o Deus cristão em todo e qualquer acaso", o espírito realmente atinge uma disciplina que lhe permite chegar a formas menos falsificadas; finalmente, que a natureza, em geral, "em sua magnificência pródiga e indiferente" é tão vasta e maleável que todas essas tentativas de ajuste, por maior conteúdo 
falsificador que tenham, atingem algum grau de correção adaptativa. Por outro lado, conquanto as exigências morais sejam sumamente arbitrárias, elas não deixam de ser sintomáticas do combate empreendido contra certas pulsões, e portanto são também uma via indireta para se abordar tais pulsões. Elas são, por assim dizer, um material valioso para o estudo filológico do "texto bomo natura".

A partir daqui, podemos fazer algumas considerações sobre o procedimento "filológico" com que Nietzsche aborda a história do pensamento sobre o humano, e que resulta numa reinvenção dessa história. $\mathrm{O}$ retrato cruelmente traçado do animal humano em BM 291 parece ser uma refutação ponto por ponto dos principais tropos que configuraram a visada tradicional metafísica. O filósofo contrapõe, primeiramente, a ideia da origem divina do homem à visão de sua animalidade; depois, inverte a visão da adequação entre a natureza e verdade, que levou a tradição a equacionar a verdade com o bem; e então, contra toda avaliação moral - espaço do humano para o qual se buscou uma fundamentação mais decididamente inquestionável, ancorada na "revelação" - levanta a suspeita de que justamente aí se vê a marca definitiva da "mendacidade" do animal humano; mas, afinal, o filósofo parece sugerir que a moral, enquanto instrumento dessa "mendacidade" e "artificialidade", deixa entrever algo positivamente verdadeiro sobre a natureza humana. A história do pensamento ocidental produziu um texto sobre o humano, um texto que merece toda a nossa desconfiança, e mesmo assim, com referência a esse texto, Nietzsche parece tirar algumas conclusões sobre o que o humano é. Uma vez que, segundo Nietzsche, a cultura metafísica colocou a "verdade de ponta-cabeça" (BM, Pr.), seu procedimento aqui consiste em colocar a cultura metafísica de ponta-cabeça. Que analogia podemos traçar entre este procedimento e o procedimento filológico?

Importante estudioso das obras filológicas de Nietzsche, James Porter oferece em Nietzsche and the Philology of the Future (2000) uma análise eloquente da atividade de Nietzsche e da tradição filológica em que se insere, que seria eminentemente uma escola de filologia cética. Essa escola toma como princípio metodológico a suspeita sistemática sobre a confiabilidade de todo e qualquer aspecto dos documentos: suspende-se em primeiro lugar o status de autenticidade de autoria de um testemunho, e então o status de pertinência do que é testemunhado. Aqui todos são culpados até que se prove o contrário, e as circunstâncias são altamente desfavoráveis a que se consiga provar qualquer coisa nesse sentido. Este é, de certa forma, o procedimento de "colocar de ponta-cabeça" as posições mais comumente aceitas pela tradição. 
A dúvida sistemática que rege a filologia converte-se, então, no caso de Nietzsche, numa dúvida quanto à própria possibilidade de fazer filologia (PORTER, 2000, p. 22). A crítica de Nietzsche se volta contra a tendência dos filólogos a fantasiarem a antiguidade ao mesmo tempo em que se aferram a "seu estimado positivismo histórico, sua fé ingênua na habilidade de reconstituir e captar o passado em sua condição original, sua afirmação temerária da própria capacidade de separar o espúrio do autêntico com alguma certeza" (PORTER, 2000, p. 9). Por mais rigorosos que sejam seus métodos, a filologia, para Nietzsche, deve renunciar à pretensão de atingir uma imagem pura, positiva, não enviesada da antiguidade. Nietzsche leva as dúvidas que pairam sobre a confiabilidade da filologia ao mais alto grau de tensão, de forma que Porter sugere que sua atividade consiste, na verdade, em uma "contra-filologia" (PORTER, 2000, p. 17), e que sua visão sobre a filologia, em geral, é de que não há para ela qualquer fundamento possível a não ser uma espécie de "vontade de filologia", nos termos do intérprete (PORTER, 2000, p. 9). Mas se a filologia parece definitivamente incapaz de reconstituir uma imagem verdadeira da antiguidade, por que filologia, afinal? Por que há ainda uma "vontade de filologia"?

Segundo Porter, não é possível compreender a atividade filológica de Nietzsche sem manter em mente seu caráter extemporâneo. A busca pelo passado empreendida pela filologia oferece uma oportunidade ímpar de compreensão da própria modernidade, e é portanto um material valioso para o tratamento de uma das questões com que Nietzsche supostamente mais se preocupou:

Uma das preocupações centrais ao longo de sua carreira, e uma que será central para esse estudo, foi determinar as formas nas quais a filosofia e a filologia são sintomáticas de hábitos culturais modernos, ideologias, e imaginações. Nietzsche talvez tenha delineado o mais corrosivo dos modelos até agora disponíveis para exumar os espectros da sociedade ocidental, na forma de uma antropologia cultural. Uma preocupação incessante com a sintomatologia do "sujeito" moderno - seus transtornos, suas ilusões, e os signos de sua presença insuprimível - é, eu acredito, o que unifica a obra de Nietzsche mais do que qualquer questão particular. (PORTER, 2000, p. 4).

O caráter extemporâneo dessa visada lança a suspeita de que nossa reconstrução dos antigos é, por um lado, sintoma da condição moderna e, por outro, a consideração de que essa condição moderna é ela mesma um 
resultado da cultura antiga. A modernidade revela-se, assim, como produto de uma antiguidade, conquanto a visão que podemos ter desta permaneça fatalmente nebulosa. Nas palavras de Porter: "A filologia não descobre o passado. Ela descobre o presente à luz da inesgotável futuridade do passado" (PORTER, 2000, p. 14). Sobre o título "filologia do futuro" (forjado pelo próprio Nietzsche para encabeçar um de seus projetos de juventude, muitos anos antes do programa de "filosofia do futuro" anunciado em Além de Bem e Mal) Porter comenta: "O que quer que Nietzsche tenha pretendido dizer além disso com esse título, a filologia do futuro implicará em investigação do passado na medida em que afeta o presente" (PORTER, 2000, p.15) ${ }^{9}$. Como isto funciona?

A meta da filologia, criticamente concebida, não é substituir uma representação mais adequada dos antigos mas trazer à tona as inadequações das representações que já temos. Os critérios de inadequação aqui não são objetivos, como seriam no caso da filologia convencional. Antes, eles são internos e sintomáticos. Inconsistências de argumento, traços de raciocínio projetivo, toques anacrônicos, motivos não expressos e possivelmente nem mesmo compreendidos - esses são os signos reveladores de uma imagem inautêntica e autoenganadora do passado. A crítica é em primeira instância cultural e psicológica, não epistemológica por natureza, e esse foco no sujeito ao invés do objeto de conhecimento é igualmente uma constante em Nietzsche mesmo além de seus dias na Basileia. (PORTER, 2000, p. 8).

Essa abordagem psicológica e culturalista é aplicada por Nietzsche em muitas camadas, na medida em que toma por objeto tanto o sujeito moderno da filologia quando os sujeitos antigos que constituem suas fontes. Porter lembra que uma das maiores contribuições de Nietzsche à filologia foi reabilitar a anedota como fonte interessante de conhecimento sobre a antiguidade: por mais que seja absolutamente impossível verificar a factualidade de uma anedota, ela seria suficiente, ou até mesmo um objeto privilegiado, para a compreensão de como certa época via certo autor, que tipo de incômodo suas ideias despertavam ali, a que tipo de tema ou companhia ele era associado.

9 Estamos diante de uma antinomia que foi registrada por Nietzsche em um de seus cadernos de estudos: "a antiguidade na verdade sempre foi entendida da perspectiva do presente - e deveria o presente agora ser entendido da perspectiva da antiguidade?” (apud PORTER, 2000, p. 15). 
À medida em que a filologia vai esclarecendo suas próprias vicissitudes e arbitrariedades, ela pode chegar, de fato, a uma nova compreensão da antiguidade. E mesmo que tenha-se renunciado à expectativa de ver os antigos exatamente como eles se viam, ou pior, ver os antigos de um ponto de vista neutro a-histórico, pode-se ainda satisfazer a expectativa de superar alguns dos preconceitos dos filólogos e produzir uma imagem realmente nova da antiguidade, e esta será igualmente portadora de uma nova verdade sobre os modernos.

Trazendo a discussão de volta para o problema do "texto homo natura", podemos agora avançar alguns pontos: o procedimento de Nietzsche consiste, muitas vezes, em tentar uma desconstrução cética da visão do humano legada pelos "velhos metafísicos apanhadores de pássaros", estando atento para os fatores do humano que essa visão mais se esforçou por encobrir, ou a que tipo de motivação não declarada ela pode servir. A tese fundamental do próprio Nietzsche, por outro lado, fundada no conceito de "vontade de poder" seria a peça chave, ao menos em BM, para a realização da tarefa de "retradução do homem de volta à natureza"; vontade de poder é o vocabulário básico do que Nietzsche anuncia como uma "nova" e "estranha" linguagem (BM 4). Essa é a um tempo uma novíssima linguagem, uma reformulação nietzschiana da tradição moderna de que é herdeiro imediato, bem como um tipo de especulação para a qual havia espaço na cultura científica de sua época; ela é, por outro lado, uma linguagem extemporânea, que busca recuperar algo encoberto pela velha linguagem metafísica, ou seja, algo da visão pré-socrática do homem integrado ao mundo da physis, e do mundo concebido como conflito, segundo o modelo do agonismo grego.

A busca pelo "eterno texto homo natura" dificilmente pode ser compreendida como a busca por um texto original ${ }^{10}$. Frente a tudo o que temos dito, se há uma coisa que não se pode dizer do homem, em linguagem nietzschiana, é que ele é "eterno". O uso da expressão aqui parece sinalizar a tentativa de escavar sob o texto atual os aspectos terríveis dessa natureza humana que, apesar de todo esforço da cultura moral metafísica, continuam atuando no homem e na cultura, ou seja, é uma expressão que refere-se à futuridade dos traços herdados desde a pré-história humana.

10 Supor tal possibilidade seria algo como tentar estabelecer a chamada "questão homérica" apostando que se pode encontrar os manuscritos completos da Ilíada e Odisseia com assinatura e firma reconhecida do poeta.

Estudos Nietzsche, Curitiba, v. 5, n. 2, p. 167-188, jul./dez. 2014 
A interpretação dessa questão proposta por Lampert até certo ponto vai ao encontro da nossa:

Nietzsche, manancial de esforços desconstrutivos para negar a fundamentalidade de qualquer texto, fala da natureza humana como um texto eterno. A natureza humana, produto de uma história evolutiva, é inerradicável por cosméticos, permanecendo presente como o que há de mais profundo independentemente do que é "rabiscado e pintado" sobre ela por escritores e artistas da humanidade a serviço da vontade básica do espírito. A vontade contrária opõe a vontade básica tornando-se senhora sobre essas interpretações, traçando a má interpretação moral de volta a seu texto pré-moral. (LAMPERT, 2001, p. 231).

O problema é que, na verdade, todas as indicações deixadas ao longo de Além de Bem e Mal sugerem que a tarefa lançada por Nietzsche não consiste numa recondução à condição pré-moral, mas numa passagem para o extramoral. E isto tem a ver com um segundo ponto aparentemente inexato da interpretação de Lampert: ao que nos parece, pode-se dizer que a natureza humana permanece "inerradicável" apesar de mas não independentemente da ação "cosmética" das interpretações morais, uma vez que estas tiveram um papel efetivo no processo de seleção social, e deixaram suas marcas. $\mathrm{O}$ impulso mesmo que impele o filósofo a tomar para si essa tarefa seria um produto tanto da seleção natural quanto da seleção social; nos referimos, é claro, ao impulso cruel de conhecer.

Com isto retornamos finalmente à questão não respondida que encerra o muito comentado aforismo 230 de $A B M$, sobre a vontade de conhecimento ela mesma. O aforismo que teve início com o estabelecimento do ponto de que o espírito tende fundamentalmente ao engano, à simplificação e à vontade de dominação, tendência contraposta por um exercício de cruel honestidade, passa à edição da tarefa de recuperação do texto homo natura $\mathrm{e}$ é concluído com a pergunta: “"Por que conhecimento, afinal?'. Todos nos perguntarão isso. E nós, premidos desse modo, nós, que já nos fizemos mil vezes a mesma pergunta, jamais encontraremos resposta melhor que..." (BM 230). A resposta a esta questão fundamental, a questão sobre o valor da vontade de verdade, representada por Édipo e a Esfinge no primeiro aforismo do livro, parece se encontrar nas primeiras linhas do aforismo seguinte: "A aprendizagem nos transforma; faz como toda alimentação, que não apenas 'conserva' -: como bem sabe o fisiólogo.” (BM 231). Ao retomar 
a metáfora da alimentação, Nietzsche indica que a resposta a essa questão na verdade já estava dada em BM 230: o espírito que se alimenta de conhecimento é capaz de transformar a vontade básica do espírito, e passa a assumir novas necessidades "fisiológicas", um novo "gosto intelectual". A busca pela verdade torna-se para ele uma necessidade vital, uma fatalidade. Uma alimentação que "não apenas 'conserva" seria aquela que favorece a expansão da "vontade de poder"; finalmente, a sugestão aqui é de que o ímpeto cruel para a verdade é igualmente um ímpeto para a dominação.

A sequência dessa consideração é um tanto surpreendente: "Mas no fundo de todos nós, 'lá em baixo', existe algo que não aprende, um granito de fatum [destino] espiritual, de decisões e respostas predeterminadas a seletas perguntas predeterminadas.” (BM 231). Segundo a interpretação de Lampert, neste ponto pouco convincente, a passagem faz referência à própria fatalidade da vontade de verdade (Cf. LAMPERT, 2001, p. 233). A nosso ver, Nietzsche aqui se refere a um ponto cego que há "em todos nós", um ponto resistente às investidas da crueldade do conhecimento, e que provavelmente tem a ver com a "fatalidade" da herança biológica e cultural de cada um. Com isto Nietzsche por assim dizer pede licença ao leitor para apresentar seu próprio ponto cego, e este, ainda mais surpreendentemente, diz respeito a suas considerações sobre "a mulher em si", pois "Em todo problema cardinal fala um imutável 'sou eu'; sobre o homem e a mulher, por exemplo, um pensador não pode aprender diversamente, mas somente aprender até o fim - descobrir inteiramente o que nele está 'firmado' a esse respeito" (BM 231). Nietzsche então concede em expor sua visão sobre o tema "desde que já se saiba que são apenas verdades minhas." (BM 231).

O que se segue é uma série de comentários prescritivos sobre a relação homem e mulher, que soam absolutamente agressivos à sensibilidade moderna. Estes comentários contêm, em primeiro lugar, críticas às tentativas de ilustração da mulher, mais precisamente, críticas às tentativas de ilustração sobre a mulher. Nietzsche prescreve neste ponto uma aceitação da disposição fundamental do espírito a não saber, não saber sobre a mulher, sob o suposto risco de revelar-se o "eterno-tedioso da mulher" (BM 232). Esta consideração expressa a intenção de impor um limite à investigação científica. Outras ocorrências bastante intrigantes incluem: "Nós, os homens, desejamos que a mulher não continue a se comprometer através do esclarecer: assim como foi cuidado e atenção masculina para com a mulher que a Igreja decretasse mulier taceat in eclesia! [que a mulher se cale na igreja!]." (BM 232); "Se a mulher 
fosse uma criatura pensante teria descoberto, cozinhando há milênios, os mais importantes fatos fisiológicos, e teria também aprendido a arte da cura!' (BM 234); 'Equivocar-se no problema fundamental 'homem e mulher', nele negar o mais profundo antagonismo e a necessidade de uma tensão hostil, e sonhar talvez com direitos iguais, igual educação, reivindicações e deveres iguais: eis um sinal típico de superficialidade" (BM 238); "ele tem que conceber a mulher como posse, como propriedade a manter sob sete chaves, como algo destinado a servir e que só então se realiza" (JGB/ABM, \$238); "Que a mulher ouse avançar quando já não se quer nem se cultiva o que há de amedrontador no homem, mais precisamente o homem no homem, é algo de se esperar e também de compreender; o que dificilmente se compreende é que por isso mesmo a mulher - degenera." (BM 239); "Pensa-se inclusive, aqui e ali, em fazer das mulheres livres-pensadores e literatos: como se uma mulher sem religião não fosse, para um homem profundo e ateu, algo totalmente repugnante ou ridículo" (BM 239).

O fato de que o capítulo "Nossas virtudes", em que Nietzsche anuncia sua tarefa de retraduzir o homem de volta à natureza seja encerrado com considerações tão deletérias, idiossincráticas e, como não dizer, moralistas, é um fato bastante perturbador ${ }^{11}$. O texto como um todo só se torna legível se não perdermos de vista as modulações com que essas considerações são apresentadas.

Toda a sequência de aforismos que encerram o capítulo é bastante peculiar. De BM 229, que trata do tema da crueldade do conhecimento até BM 239, que encerra as considerações programáticas sobre o papel da

11 Lampert tem uma interpretação bastante diferente desse ponto, talvez por ser bem mais simpático às colocações de Nietzsche a este respeito. Segundo o autor, Nietzsche não avança suas considerações sobre a mulher como uma mera idiossincrasia nem como algo alheio às considerações anteriores sobre o "texto homo natura". Ou seja, o autor toma literalmente as afirmações nietzschianas, e as interpreta como expressão de uma verdade sobre a natureza do homem e da mulher, verdade que serviria de fundamentação para uma espécie de "política sexual". Lampert chega mesmo a traçar um paralelo entre homem e mulher e as duas disposições do espírito, associando a mulher à vontade básica de engano e o homem à crueldade do conhecimento. Não acompanhamos o autor nessa interpretação porque parece-nos muito clara a modulação com que Nietzsche apresenta tais considerações: elas não são apresentadas como parte do texto natural, mas como parte daquilo que não se consegue traduzir para uma linguagem mais verdadeira, por se estar num terreno em que no máximo é possível dar um testemunho de si mesmo, dos limites sócio-históricos e culturais que nos impedem de nos livrarmos de certas crenças e disposições. No entanto não duvidamos da afirmação de Lampert quanto à conotação política desse tema; é provável que Nietzsche de fato tivesse em mente algo como um plano de "política sexual". 
mulher na cultura europeia, passando por BM 230, que anuncia a tarefa de retradução do homem à natureza, vemos Nietzsche se expressar de modo muito mais pessoal que de uso. Toda essa sequência tem um tom confessional. E se é verdade que podemos afirmar, juntamente com Porter (2000, p. 13) que o texto nietzschiano leva o leitor a uma profunda crise de identidade dada a dificuldade de estabelecer o peso que se deve conferir a suas muitas vozes, nesse trecho de Além de Bem e Mal parece-nos que ouvimos um Nietzsche em sua própria voz, ou na voz mais pessoal possível. Mas essa confissão em voz própria tem dois aspectos: ela fala primeiramente da possibilidade de avançar efetivamente o campo do conhecimento sobre o humano, e então passa aos limites desse avanço, limites que apontam para a "grande estupidez que somos, para nosso fatum espiritual, o que não aprende “lá embaixo"” (BM, \$231). E é como uma "grande estupidez" que apresenta suas considerações sobre a mulher. Por mais que as afirmações de Nietzsche sobre a mulher sejam discutíveis, e de valor duvidoso, não se pode acusá-lo aqui de falta de honestidade. Enquanto o exercício de honestidade no conhecimento e no autoconhecimento seria uma expressão de crueldade, o reconhecimento da própria estupidez seria uma "gentileza" endereçada a si mesmo; ambos os movimentos são, na verdade, atos de honestidade sobre as próprias capacidades e limites. E ainda, o filósofo parece atribuir valores igualmente relevantes tanto para nossa mais profunda crueldade no conhecer quanto a nossa "grande estupidez", e papeis igualmente relevantes para ambos na reinvenção da cultura. Aqui vemos Nietzsche atingir seu próprio ideal do que é fazer filosofia, ao expressar sua própria "magnífica tensão do espírito". É talvez por não renunciar a qualquer um dos lados dessa tensão que a filosofia nietzschiana se coloca além do ceticismo, além da crítica (Cf. BM 208), além de bem e mal. É por isto que os filósofos do futuro, entre os quais Nietzsche certamente se inclui como precursor, "bem poderiam, ou mesmo mal poderiam, ser chamados de tentadores. Esta denominação mesma é, afinal, apenas uma tentativa e, se quiserem uma tentação." (BM 42)

12 Significativamente, esse aforismo em que Nietzsche anuncia suas expectativas quanto à nova filosofia por ele inaugurada é imediatamente sucedido por uma reafirmação da vontade de verdade: "Serão novos amigos da 'verdade' esses filósofos vindouros? Muito provavelmente: pois até agora todos os filósofos amaram suas verdades. Mas com certeza não serão dogmáticos.” (BM 43). A partir daí, o aforismo passa a uma consideração sobre o quanto há de pessoal na busca pela verdade, e desvaloriza as tentativas de universalização das verdades filosóficas. As verdades do filósofo, o autoconhecimento e projeção de sua personalidade, incluem tanto aquilo que pode ser aprendido

Estudos Nietzsche, Curitiba, v. 5, n. 2, p. 167-188, jul./dez. 2014 
Para apreciar algo da riqueza do programa filosófico lançado em Além de Bem e Mal deve-se estar atento ao fato de que cada uma de suas grandes teses são investidas de modulações bastante diferentes. Sua principal tese talvez seja a "vontade de poder", que é apresentada como um experimento de pensamento bastante rigoroso, com possíveis aplicações no campo científico, e talvez até mesmo como insight fundamental de uma nova psicologia; at last but not least, esta é uma tese que se destina ao estudo das relações hierárquicas de dominação estabelecidas entre diferentes formas de vida, diferentes valorações, ou diferentes campos da atividade humana, como filosofia e ciência. Já o tema do "eterno retorno" se refere a uma espécie de vivência mística marcada por uma disposição erótica para com a vida, experiência afirmativa desejável numa época em que a vida espiritual deixa de ser conduzida pelas religiões. A "retradução do homem à natureza" ou recuperação do "terrível texto básico bomo natura" é uma tarefa que o filósofo se coloca num momento de total honestidade quanto às possibilidades do conhecer. Cada um desses temas é apresentado com diferentes tonalidades, diferentes investidas retóricas e sinalizadores que alertam o leitor para seu peso no interior do programa filosófico em questão. Tais sinalizadores, contudo, sempre colocam um desafio de decifração, que força o leitor a engajar-se pessoalmente no texto e encontrar sua veia de entrada. Além de Bem e Malé um testemunho em grande estilo de que, numa época de conquistas científicas, no limiar da passagem para uma cultura pós-metafísica e extramoral, o filosofar é decididamente possivel.

\section{Referências}

CHAVES, E., Considerações sobre o ator: uma introdução ao projeto nietzschiano da fisiologia da arte. Trans/Form/Ação, São Paulo, 30(1): 51-63, 2007.

D'IORIO, P., La superstition des philosophes critiques. Nietzsche et Afrikan Spir. Nietzsche-Studien, 22 (1):257-294 (1993)

no exercício sempre algo cruel de buscar o conhecimento quanto o que não pode ser aprendido, o ponto cego, o "grão de fatum" que o filósofo nunca pode esclarecer completamente, mas que é levado em conta como uma peça das mais importantes no exercício de autoconhecimento. E como os limites entre aprendizagem e "estupidez" não se dão a conhecer de antemão, este será sempre um exercício de experimentação. 
LAMPERT, L., Nietzsche's Task: An Interpretation of Beyond Good and Evil. Yale University Press, 2001.

MATTIOLI, W., O devir e o lugar da filosofia. Kriterion, Revista de Filosofia, vol. LIV, no 128 , pp. 321-348, julho a dezembro, 2013.

NIETZSCHE, F., Além do Bem e do Mal - prelúdio a uma filosofia do futuro. Tradução, notas e posfácio de Paulo César de Souza. São Paulo: Companhia das Letras, 2005.

NIETZSCHE, F., O Caso Wagner - um Problema para Músicos. Tradução, notas e posfácil Paulo César de Souza - São Paulo: Companhia das Letras, 1999.

PORTER, J. I., Nietzsche's Philology of the Future. Stanford: Stanford University Press, 2000.

RAMAT'TIOTI, B. L., Nietzsche: Fisiologia como fio condutor. Estudos Nietzsche, Curitiba, v. 3, n. 1, p. 65-90, jan./jun. 2012.

RICHARDSON, J., Nietzsche's new Darwinism. New York: Oxford University Press, 2004.

\section{Alice Medrado}

Doutoranda em filosofia pela FAFICH/UFMG, e-mail: alicemedrado@yahoo.com.br

Recebido: $12 / 02 / 2015$

Received: 02/12/2015

Aprovado: 25/04/2015

Approved: 04/25/2015 